Down Syndrome Research and Practice Vol. 5, No. 2, pp 71 - 77.

(c) The Down Syndrome Educational Trust

Printed in Great Britain. All Rights Reserved.

ISSN: 0968-7912 (1998) 5:2

\title{
HARDINESS IN FAMILIES WITH AND WITHOUT A CHILD WITH DOWN SYNDROME
}

\author{
Anna Bower \\ Queensland University of Technology, Brisbane, Australia \\ David Chant and Sara Chatwin \\ The University of Queensland, Brisbane, Australia
}

\begin{abstract}
The paper reports on mothers' perceptions, ideas and beliefs about the hardiness and resilience of their families, in families with and without a child with Down syndrome. Mothers in Australia and New Zealand responded to The Family Hardiness Index (FHI), a standardised psychometric instrument, suitable for the purpose of this investigation. Furthermore the Australian cohort responded to an in-depth interview schedule, in which family hardiness was the main feature. Results suggest that there are minimal differences between families with and without a child with disability. Furthermore, mean differences between the two groups were not statistically significant. These findings point to increasing evidence that the previously identified pathology and dysfunction in families with a child with disability cannot be easily generalised to all families with disability, and in fact there exists emerging evidence that the presence of disability can have the opposite effect and provide families with a sense of hardiness or resilience. The close agreement between the means obtained in this study and the means of the published comparative data of the index suggests that the $\mathrm{FHI}$ is a suitable instrument to complement full family hardiness assessment.
\end{abstract}

Keywords: Down syndrome, The Family Hardiness Index, families, resilience

\section{Introduction}

It has generally been acknowledged that the presence of a child with disability influences and alters the dynamics of family life (Fewell, 1986; Fisman \& Wolf, 1991; Hayes, 1998) to the extent that researchers have identified a range of differences in family functioning for those families who have a child with disability (e.g. Crnic, Friedrich \& Greenberg, 1983), and many of these studies on intra-familial interaction and relationships have suggested negative or pathological responses by members of families who have a child with disability. Among a wide range of identified risk factors for families with disability are the negative effects on the marital relationship (Turnbull \& Turnbull, 1986), psychological maladjustment of siblings (Fewell, 1986; Lobato, 1983; Stoneman, Brody, Crapps \&
Malone, 1991), increased incidence of depression and anxiety of family members (Fisman \& Wolf, 1991; Lobato, Barbour, Hall \& Millar, 1987), and social isolation of the family (Cant, 1992).

Hampson, Hulgus, Beavers and Beavers (1988) summarised the literature of families at risk as follows:

much of the available literature dealing with families of chronically ill, mentally retarded, or functionally disabled children points to the strained feelings, chronic stresses, and potentially maladaptive patterns of adjustment, for which the entire family, a specific sibling, or parental members, appear to be 'at risk' (p. 32).

While it cannot be disputed that the arrival of a child with a disability results in some distress for 
most family members, it may be argued that families also have the capacity to make the necessary adjustments and accommodations which are necessary to keep the family functional (Gallimore, Weisner, Bernheimer, Guthrie \& Nihira, 1993). There is emerging evidence that, following an initial difficult period of shock as a result of the arrival of a child with Down syndrome, many families show evidence of coping during the subsequent stages of early and middle childhood (Mahoney, O'Sullivan \& Robinson, 1992). In fact, almost three decades ago Hewett (1970) noted that following this initial period, many families make a remarkable adjustment to this situation and show extraordinary levels of resilience. This suggests that it may in fact be the presence of disability and the need to address the related demanding issues which results in the heightened resilience that many families experience (Bower, 1996). The belief that disability results in family dysfunction, or indeed pathology, has been so well established, that it has resulted in the tendency for professionals and the community to respond inappropriately to the needs of these families (Turnbull \& Turnbull, 1986). Moreover, families with and without a child with disability cannot be viewed as if they were of heterogeneous nature, and while trends can be established, variations in the experiences and lives of families must be acknowledged. Gestures of sympathy rather than empathy and insensitivity in communication with families about disability issues related to families' ability to cope, are examples of entrenched ways of viewing the functioning of families with a child with Down syndrome.

More recent research has supported the acknowledgement of strengths rather than weaknesses of families with a child with disability (Hanline, 1991; Schwab, 1989; Sloper \& Turner, 1993). One of the difficulties associated with studies that examine families with a child with disability is that most researchers have studied this problem at the time when families are first confronted with this difficulty. Another sensitive transition time for families that has been widely researched occurs when the child reaches adolescence. Few studies appear to have focused on the 'in-between' period of family development, during the middle childhood period of the child with disability, by which time, following an often traumatic initial experience, families have had the opportunity to regain their balance and consequently their resilience. It is suggested that family resilience tends to be at a peak during this period, and that families strongly resent the patronising attitudes they often experience from the community
(Bower, 1996).

In families with a child with Down syndrome mothers have traditionally been the major carers, thereby placing considerable additional responsibilities and stress on mothers (Gregory, 1991; Hayes, 1998). While the support and contributions that fathers and other family members may make to the care of a child with disability is acknowledged, a large number of mothers, who were surveyed about their roles and responsibilities related to the child with disability, indicated their major involvement with the disabled child in the day-to-day running of family life. They described these roles and responsibilities predominantly as being organiser and promoter of health care, education and social activities (Bower, 1996). The acceptance and performance of this range of roles by mothers requires a fair degree of personal resilience, which they appear to experience when they have the support of their family and view their family unit as demonstrating 'hardiness'.

\section{The Concept of 'Resilience' and 'Family Hardiness'}

The concept of individual hardiness was originally developed by existential psychologists (e.g. Allport, 1955; Fromm, 1947; Kobasa \& Maddi, 1977). Hardiness is a term that was first identified in the literature describing personal resilience in terms of the health status of individuals (Kobasa, 1979). Kobasa and her colleagues argued that the ability to be resilient increases individuals' chances for physical and psychological health. In this context hardiness also describes the ability to cope. On the other hand, the absence of resilience may be characterised by increased levels of risk factors to physiological and psychological well being (Banks \& Gannon, 1988; Kobasa, Maddi \& Kahn, 1982; McCubbin \& McCubbin, 1992). Kobasa (1979) describes the characteristics of 'hardiness' as follows:

Hardy persons are considered to possess three general characteristics: (a) the belief that they can control or influence the events of their experience, (b) an ability to feel deeply involved in or committed to the activities of their lives, and (c) the anticipation of change as an exciting challenge to further development (p. 3).

While the characteristics of hardiness may be attributed to individuals they may also be attributed to groups of people such as families. Coping strategies observed in families with a Down syndrome child have been identified in a range of studies (Quine \& Pahl, 1991; Sloper, 
Knusson, Turner \& Cunningham (1991). The functioning of a family unit may either empower or disempower its individual members.

McCubbin, McCubbin \& Thompson (1986)

developed the Family Hardiness Index (FHI) to measure the characteristics of hardiness as a resilience and adjustment resource. Furthermore, McCubbin et al., (1986) argue that family hardiness describes the internal strengths of the family unit, characterised by a sense of control over life events. It is suggested here that such a sense of control results in empowerment and resilience of families. Moreover, it is proposed that by assessing mothers' perceptions of their family's hardiness, their judgments may be valid indicators of family functioning.

The FHI was initially developed and used for an investigation of family traditions, celebrations and routines in families not at risk. In this study mothers' perceptions of their families' hardiness or resilience are compared and contrasted by two groups of mothers, those with and those without a child with Down syndrome. The study was conducted simultaneously in Brisbane, Australia and Auckland, New Zealand by a team of researchers. This allowed for: (a) some limited scope for cross cultural comparison; and (b) an increase in sample size for statistical power.

The central questions addressed in this study were: (a) are mothers' perceptions of family hardiness influenced by the presence of a child with Down syndrome?; (b) can differences among the subscales be established for the two identified groups, and if so, are they statistically significant?; and (c) are the perceptions consistent across two geographically different but culturally similar samples? Answers to these questions, although based on a relatively small sample, will facilitate a better understanding of mothers' reports of family hardiness.

\section{Method \\ Participants}

The participants in this study include mothers in Australia and New Zealand. Mothers who have a child with Down syndrome were identified from registers held by the Schonell Special Education Research Centre at The University of Queensland, which is conducting a longitudinal study of children with Down syndrome and their families. Similarly, mothers in the comparison groups were identified from registers of previous studies, school registers and self referrals by seeking voluntary participants for the study from local schools. For this study families with a child with Down syndrome in the middle childhood period (aged between 5 years and 15 years 11 months) were selected. Families in the two groups were matched on a case by case basis against the following sets of variables: (1) gender, age range and birth order of the child with Down syndrome; and (2) mother occupation skills level (Hollingshead, 1975), and mother marital status. The Australian group consisted of a total of 17 mothers from Brisbane, who have a child with Down syndrome. In addition 40 mothers who do not have a child with disability and met the family matching criteria were contacted and 37 agreed to participate in the study. The New Zealand sample was constructed similarly and consisted of 28 mothers from Auckland who have a child with Down syndrome and 56 mothers without a child with disability. The target children in the comparison families were matched on the same characteristics of gender, age, and birth order.

\section{Instrument}

The FHI (McCubbin et al., 1986) assesses the three characteristics of hardiness identified by Kobasa (1979), control, commitment and challenge. Family control aims to measure the family's sense of being in control of family life rather than being conditioned by external events and circumstances. Family commitment assesses the family's sense of internal strengths, dependability and ability to work together, hence the authors' term co-oriented commitment. Challenge measures the family's ability to be resourceful and being able to embrace new ideas and assimilate them into their existing schemata. In addition, the scale adds a fourth characteristic, confidence, which McCubbin et al. (1986) argue: "measures the family's sense of being able to plan ahead, being appreciated for efforts, their ability to endure hardships and experience life with interest and meaningfulness" (p. 125). While the authors of the FHI do not provide normative data, they are confident that the sample of 304 families used in the initial study does provide meaningful comparison data and publish means and standard deviations. Internal reliability for the FHI is reported as .82 (Cronbach's alpha). The FHI is presented as a 20 statement questionnaire that requires the participants to respond on a 4-point Likert style scale, ranging through $0=$ false, $1=$ mostly false, $2=$ mostly true, $3=$ true. In addition, the mothers in the Australian cohort responded to an interview in which they were given the opportunity to elaborate on issues related to family hardiness.

\section{Procedure}

The questionnaire is easy to understand and designed to be used either as an interview 
questionnaire or as a mailed instrument. The instrument was used in its original form and did not require culturally pertinent modification. In this study all the Australian participants had previous contact with the researcher through a personal interview and therefore were familiar with the research project. The participants were contacted by phone to ascertain their willingness to further participate in the study by responding to the questionnaire. The previous contact with the participants by the same researcher resulted in an exceptionally high response rate (93\%) for the Australian sample. The questionnaire was mailed to each participant with an introductory letter explaining the nature of this research program and basic instructions on how to respond to the questions. In the New Zealand sample the questionnaire was administered by a researcher who visited each family personally.

\section{Results}

Means and standard deviations for the total scale and FHI sub-scales for both the Australian and the New Zealand sample, as well as the pooled sample, are presented in Table 1. countries on the sub-scales of Co-oriented Commitment $(\mathrm{F}=9.13 \mathrm{df}=1,134, \mathrm{p}=.003)$, Challenge $(\mathrm{F}=5.46, \mathrm{df}=1,134, \mathrm{p}=.02)$, and the FHI total score $(\mathrm{F}=10.5, \mathrm{df}=1,134, \mathrm{p}=$ .002), with the New Zealand sample showing greater mean scores. The mean differences between countries, pooled over disability status, are shown in Table 1, and these differences are expressed as percentages of the possible range of scores. The percentages corresponding to statistically significant mean differences are of the order of $6 \%$, which correspond roughly to a 0.25 change on a $0-4$ scale (the underlying metric of individual FHI items), and thus appear to be of only marginal substantive significance. Of particular interest is the close agreement between the FHI mean scores in our study and the comparative data provided by the authors of the scale (see Table 1). While the authors of the scale acknowledge the limited sample used to establish normative data (responses from 304 families), the close agreement with the results of this present study and those of the scale suggests a reasonable degree of validity for this index as an appropriate complementary strategy for assessing family hardiness and resilience.

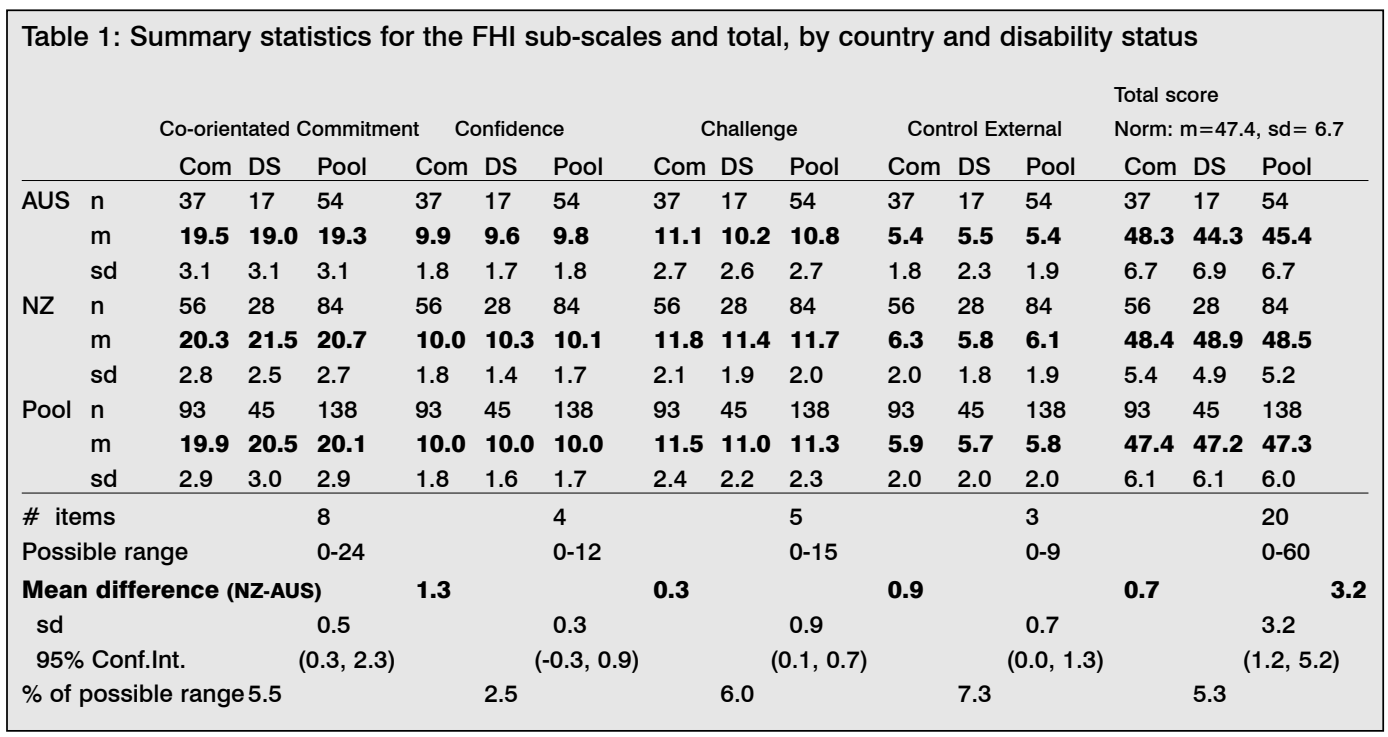

To examine whether mean perceived hardiness differs between the reports of mothers with and without a child with disability for the Australian and New Zealand groups, multivariate and univariate analyses of variance were used. The only significant mean differences among the four sub-scales were with respect to country $(\mathrm{F}=$ 3.22 , df $=4,131, p=.02$ ), not with respect to disability status or the interaction of country and disability status. Analyses of variance showed statistically significant mean differences between

\section{Discussion}

The absence of significant differences between families with and without a child with Down syndrome points clearly towards an emerging acknowledgment of similarities in family dynamics, rather than difference. While this evidence does not rule out difficulties that are experienced at specific times in the life of a family, it never the less strengthens the assumption that all families experience difficulties in their interactions and experiences 
within, and external to, family life. In order to study family functioning in terms of resilience and hardiness it is of importance to recognise that hardiness is not only influenced by the presence or absence of a child with Down syndrome. How well mothers believe their family copes is equally dependent on a wide range of other factors, unrelated to disability. It is therefore important to view the presence of a child with Down syndrome in context, and this context may vary from family to family, depending on individual circumstances. It appears then that a family's hardiness, which describes the resilience and ability to cope with aversive situations and experiences, is a complicated construct to assess. Because of the focus on mothers as the major carers of young families, in this study mothers were the only family members surveyed in terms of their personal perceptions of the hardiness and resilience of their family. The reported results suggest the need to extend these findings to examine the perceptions, ideas and beliefs of other family members, to obtain a more balanced view of the family dynamics involved in this particular issue. It is acknowledged that this study provides merely a 'snapshot' of family resilience. Data for this study was collected on only one occasion, and the results do not generalise to a more extended period of family life. This study aims to provide some insight into mothers' perceptions about family hardiness during the period of their children's middle childhood. The remarkable consistency between mothers' responses in the two regions suggests cultural similarity, in that the mothers share similar perceptions and experiences of nurturing a family.
The overall results from this study provide additional support for the emerging understanding that the presence of the disability of a child, in this case Down syndrome, is not an exclusive indication of unusual levels of hardiness in family functioning. While this study suggests that the use of the FHI is a suitable instrument, further research into the concept of family resilience is required, first, by employing a range of suitable instruments and second, by examining, comparing and contrasting the perceptions of different family members. Our study is contributing support to the emerging view that the presence of a child with disability, particularly Down syndrome can no longer be seen as the universal catalyst for family difficulties, or indeed family dysfunction.

\section{Correspondence:}

Anna M. Bower PhD. School of Early Childhood. Queensland University of Technology. Locked Bag \#2. Red Hill, Queensland. 4059.

AUSTRALIA. (Telephone: +61 73864 3620, Fax: +61 73864 3989, E-mail:

a.bower@qut.edu.au)

\section{References}

Allport, G.W. (1955). Becoming: Basic considerations for a psychology of personality. New Haven, $\mathrm{CN}$ : Yale University Press.

Banks, J. K. \& Gannon, L.R. (1988). The influence of between stressors and psychosomatic symptomatology. American Journal of Community Psychology, 16, 25-37.

Bower, A. (1996). A comparative study of mothers' beliefs and ideas about mothering in families with and without disability. Unpublished doctoral dissertation, The University of Queensland, Australia.

Cant, R. (1992). Friendship, neighbouring and the isolated family: The case of families with disabled children. International Journal of Sociology of the Family, 22, 31-50.

Crnic, K.A. Friedrich, W.N. \& Greenberg, M.T. (1983). Adaptation of families with mentally retarded children: A model of stress, coping, and family ecology. American Journal of Mental Deficiency, 88, 125-138.

Fewell, R.R. (1986). A handicapped child in the family. In R. R. Fewell \& P. F. Vadasy (Eds.), Families of handicapped children: Needs and supports across the life-span (pp. 3-34). Austin: Pro-ED. 
Fisman, S. \& Wolf, L. (1991). The handicapped child: Psychological effects of parental, marital and sibling relationships. Psychiatric Clinics of North America, 14, 199-217.

Fromm, E. (1947). Man for himself. New York: Holt, Rinehart and Winston.

Gallimore, R., Weisner, T.S., Bernheimer, L.P., Guthrie, D. \& Nihira, K. (1993). Family responses to young children with developmental delays: Accommodation activity in ecological and cultural context. American Journal on Mental Retardation, 98, 185-206.

Gregory, S. (1991). Challenging motherhood: Mothers and their deaf children. In A. Phoenix, A. Woollett \& E. Lloyd (Eds.), Motherhood: Meanings, practices and ideologies (pp. 123-142). London: Sage.

Hampson, R.B., Hulgus, Y.F., Beavers, W.R. \& Beavers J.S. (1988). The assessment of competence in families with a retarded child. Journal of Family Psychology, 2, 32-53.

Hanline, M.F. (1991). Transitions and critical events in the family life cycle: Implications for providing support to families of children with disabilities. Psychology in the Schools, 28, 53-59.

Hayes, A. (1998). Disabilities and Families. In A. Ashman \& J. Elkins (Eds.), Educating children with special needs (3rd ed.) pp. 39-66. Sydney: Prentice-Hall.

Hewett, S. (1970). Families with a handicapped child. Allen \& Unwin.

Hollingshead, A.B. (1975). Four factor index of social position. Unpublished Manuscript. Yale University, Department of Sociology.

Kobasa, S.C. (1979). Stressful life events: Personality and health: An inquiry into hardiness. Journal of Personality and Psychology, 37, 1-11.

Kobasa, S. C., Maddi, S. R. \& Kahn, S. (1982). Hardiness and health: A prospective study. Journal of Personality and Social Psychology, 42, 168-177.

Kobasa, S. C. \& Maddi, S. R. (1977). Existential personality theory. In R. Corsini (Ed.), Current personality theories. Ithaca, IL: Peacock.

Lobato, D. (1983). Siblings of handicapped children: A review. Journal of Autism and Developmental Disorders, 13, 347-364.

Lobato, D., Barbour, L., Hall, L. J. \& Millar, C.T. (1987). Psychological characteristics of preschool siblings of handicapped and nonhandicapped children. Journal of Abnormal Child Psychology, 15, 329338.

Mahoney, G., O'Sullivan, P. \& Robinson, C. (1992). Family environments of children with disabilities: Diverse but not so different. Topics in Early Childhood and Special Education, 12, 386-402.

McCubbin, M.A., \& McCubbin, H.I. (1992). Families coping with health crises: The resiliency model of family stress, adjustment and adaptation. In C. Danielson, B. Hamel-Bissell, \& P. Winstead-Fry (Eds.), Families, health and illness.(pp.21-63). New York: Mosby.

McCubbin, M.A., McCubbin, H.I. \& Thompson, A.I. (1986). FHI: Family Hardiness Index. In H.I. McCubbin \& A.I. Thompson (Eds.), Family assessment inventories for research and practice (2nd ed.) pp. 124-130. Madison: University of Wisconsin.

Quine, L., \& Pahl, J. (1991). Stress and coping in mothers with a child with severe learning difficulties: A test of Lazarus' transactional model of coping. Journal of Community and Applied Social Psychology, 1, 57-70.

Schwab, L.O. (1989). Strengths of families having a member with a disability. Journal of the Multihandicapped Person, 2, 105-117.

Sloper, P., \& Turner, S. (1993). Risk and resistance factors in the adaptation of parents of children with severe physical disability. Journal of Child Psychology and Psychiatry, 34, 167-188.

Sloper, P., Knussen, C., Turner, S., \& Cunningham, C.C. (1991). Factors related to stress and satisfaction with life in families of children with Down syndrome. Journal of Child Psychology and Psychiatry, 32, 655-676. 
Stoneman, Z., Brody, G.H., Davis, C.H., Crapps, J.M. \& Malone, M. (1991). Ascribed role relations between children with mental retardation and their younger siblings. American Journal on Mental Retardation, 95, 537-550.

Turnbull, A.P. \& Turnbull, H.R. (1986). Families, professionals and exceptionality: A special partnership. Columbus, Ohio: Merrill. 